\title{
The Factors Involved in the Sense of Subjective Wellbeing (A Survey of 250 Subjects)
}

\author{
Ashkan Farhadi ${ }^{1, *} \&$ Sohrab Mobarhan ${ }^{2}$ \\ ${ }^{1}$ Section of Gastroenterology and Nutrition, University of California, Irvine, USA \\ ${ }^{2}$ Division of Digestive Diseases Director, The Coleman Foundation Comprehensive Clinic for Gastrointestinal \\ Cancers Rush University Medical Center, USA \\ *Correspondence: Memorial Care Medical Group, 722 Baker St. Costa Mesa, CA 92626, USA. Tel: 1-714-966-9506. \\ E-mail: ashkan_farhadi@IhaveIBS.com
}

Received: October 9, 2016

doi:10.5430/wjss.v4n1p14
Accepted: November 7, 2016 Online Published: November 29, 2016

URL: http://dx.doi.org/10.5430/wjss.v4n1p14

\begin{abstract}
Background: There is little question that a close relationship exists between level of happiness, mental health, and overall success. The prioritization and order of life's most important qualities significantly varies among individuals. In this study, we investigated what is regarded as the most important aspect of life and what things make people happy.

Method: We asked two questions in a short survey: "What is the most important thing in life?" and "What makes you the happiest?" We recruited study subjects from Orange County, California and from a rural community in Panama during a medical missionary visit. The 253 adult individuals in this study were asked to rank the provided choices from 1 to 5 based on their perceived importance.

Result: $65 \%$ of the participants were female. Family was by far the most important aspect of life among all groups and individuals (59\% selected this as the first choice). This was followed by health (14\%) and faith (13\%). Family ranked significantly higher among females compared to males. Health was much more appreciated and ranked higher in older adults than in other age groups. The top three things that make people happy were the need to be loved, having someone to love, and a sense of financial security. When comparing data from an affluent region in US to a rural sample from Panama, we did not find any significant differences in the importance of aspects in life or in things that make people happy.

Conclusion: In this preliminary study, we found that there is little difference in the things people regard as the most important thing in life and the things that make them happy among different age groups or gender. In addition, despite thousands of miles of geographical separation and a very wide socioeconomic and educational gap between the two population groups in our study, there was no significant difference between what people regard as the most important thing in life and the things that make them happy.
\end{abstract}

Keywords: Subjective Wellbeing, Happiness, Survey

\section{Introduction}

Subjective wellbeing and happiness are some of the concepts that are closely associated with mental health and overall wellbeing (Diener and Tay, 2015; Zautra and Hempel, 1984), and it is not surprising that there is a close relationship between the level of happiness, overall functioning, and feeling of success in humans (Lyubomirsky et.al., 2005). It is now well known that a positive mental attitude and happiness leads to achievement of success across multiple life domains and those people who are successful are, in general, happier individual. Regardless, the intertwining nature of success and happiness are both closely connected to achieving the objectives that people perceive as the most important things in life, and there is no question that the prioritization and order of the most important things in life varies considerably among individuals. However, there are some similarities in the important things in life based on age group, gender, place of abode, and the level of income (Diener and Tay, 2015; Ryff, 1989; 
Hogan et. al., 2016). For example, it has been shown that the things that are important to people who live in cities are substantially different from those that live in rural areas (Hogan et. al., 2016). In this study, we carried out a brief survey to determine the things that people consider to be the most important in life along with an inquiry into aspects of living that make people the happiest.

\section{Method}

253 individuals recruited for this study at two different locations (USA and Panama) completed the survey. In the US, rather than asking patients to participate, the questionnaires were distributed among friends and colleagues who asked their friends and family members to fill in the questionnaire. 216 test subjects were recruited from Orange County, California, and the rest from a rural community in Panama who were visited during a medical mission to this area. The second group received a Spanish translation of the questionnaire, which was distributed among patients and their family members. The research committee of Global Medical brigade who sponsored the mission approved the administration of the questionnaires. The study subjects were adults between 18 and 87 years old.

The questionnaire was devoid of any identifier questions to ensure participant anonymity. There were a few questions concerning demographic information, including age, gender, level of education, occupation, and country of residence. The two main questions: "What is the most important thing in life?" and "What makes you the happiest?" came next and the participants were asked to rank the provided choices from 1 to 5 based on their perceived importance. The first questions had eight provided choices to select from and the second question had 10 choices for selection (see Table 1 and Table 2). There was also an option to add a write-in choice for cases where a participant might feel there could be an alternative to the choices. We asked the participant to rank the top five choices for each question.

We asked the participants to fill in the questionnaire using a pen. Five questionnaires were considered to be incomplete and were excluded from the survey, and then the rest of the data were entered into an Excel spreadsheet. We used Chi squared analysis and a two-sided T-test for comparison of the percentages and ranking among the study groups; a p value less than 0.05 was considered significant.

Table 1. The Choices and Their Description for the Question: "What is the Most Important Thing for You?"

\begin{tabular}{|c|c|}
\hline Survey choice & Choice description \\
\hline Family & Your parents and sibling or if you have a family of your own, your spouse and kids \\
\hline Relationship & $\begin{array}{l}\text { Your relationship with friends, siblings, parents, kids or your romantic relationship with } \\
\text { your significant other }\end{array}$ \\
\hline Faith & Your religion, ideology and belief \\
\hline Assets & $\begin{array}{l}\text { Your money, house, car, belongings, retirement saving and all you have collected up to } \\
\text { now }\end{array}$ \\
\hline Happiness & Your happy feeling and content from what you have and who you are \\
\hline Responsibility & $\begin{array}{l}\text { Your words, your promises, your duties as a parent, a friend, a partner, a coworker or a } \\
\text { citizen }\end{array}$ \\
\hline Education & Your formal academic education or informal knowledge. What you have learned so far \\
\hline Health & $\begin{array}{l}\text { Your responsibility to your body to protect \& maintain your ability or do the tasks in } \\
\text { hand and enjoy your life }\end{array}$ \\
\hline
\end{tabular}


Table 2. The Choices and Their Description for the Question: "What Makes you the Most Happy Person?”

\begin{tabular}{|c|c|}
\hline Survey choice & Choice description \\
\hline Being Financially secure & $\begin{array}{l}\text { Being able to live a life without the worries for financial problems and providing } \\
\text { necessities without trouble }\end{array}$ \\
\hline Being loved & Being truly loved by one or group of people for who you really are \\
\hline Having someone to love & $\begin{array}{l}\text { Have one or more people that you love so much that you can sacrify for them } \\
\text { without a second thought }\end{array}$ \\
\hline Being famous & $\begin{array}{l}\text { Being well known by peers, friend and family or being famous at local, national or } \\
\text { international level }\end{array}$ \\
\hline Having a passion & $\begin{array}{l}\text { Having an intense interest in pursuing a sport, an art, act (studying, designing, etc.) } \\
\text { or collecting something }\end{array}$ \\
\hline Having a dream job & Having a job that has been a dream for you as long as you remember \\
\hline Being respected & Having the respect of peers, friends and family \\
\hline $\begin{array}{l}\text { Being useful to } \\
\text { something or someone }\end{array}$ & $\begin{array}{l}\text { Being able to be effectively useful to solve someone problem or to be beneficial to } \\
\text { something or someone }\end{array}$ \\
\hline $\begin{array}{l}\text { Having more pleasure } \\
\text { and enjoyment }\end{array}$ & $\begin{array}{l}\text { Having more pleasures such as good food, good time, sex, having good company, } \\
\text { watch good movie, see the world }\end{array}$ \\
\hline Being attractive & $\begin{array}{l}\text { Having a look that you enjoy in the mirror and feel that others also enjoy and } \\
\text { admire }\end{array}$ \\
\hline
\end{tabular}

\section{Results}

The majority of the participants were college-educated, affluent individuals except for the smaller group of individuals from rural parts of Panama; most of those were able to read and write and were either farmers or housewives. 65\% of the participants were female and the rest were male. The majority of the participants were young to middle aged adults. The age and gender distributions of the participants are shown in Figure 1 and 2.

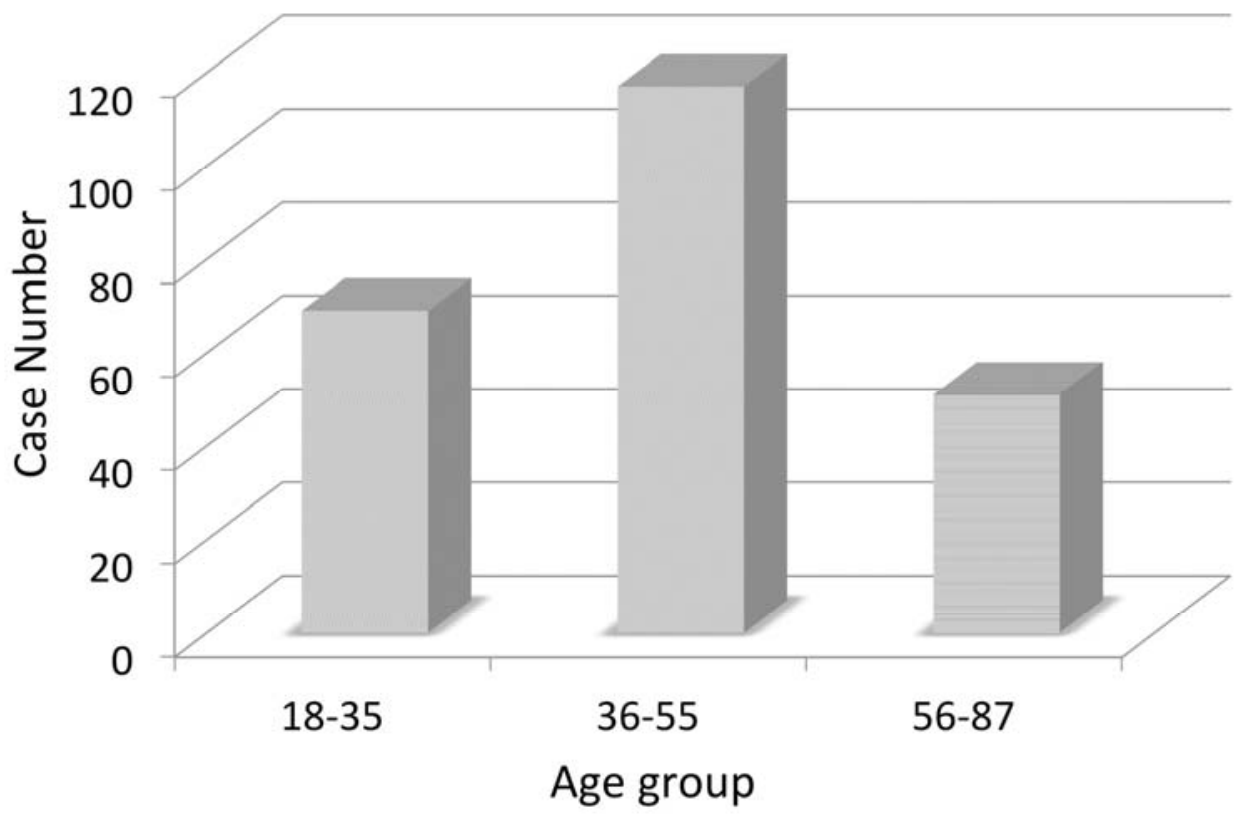

Figure 1. Age Distribution of the Study Subjects 


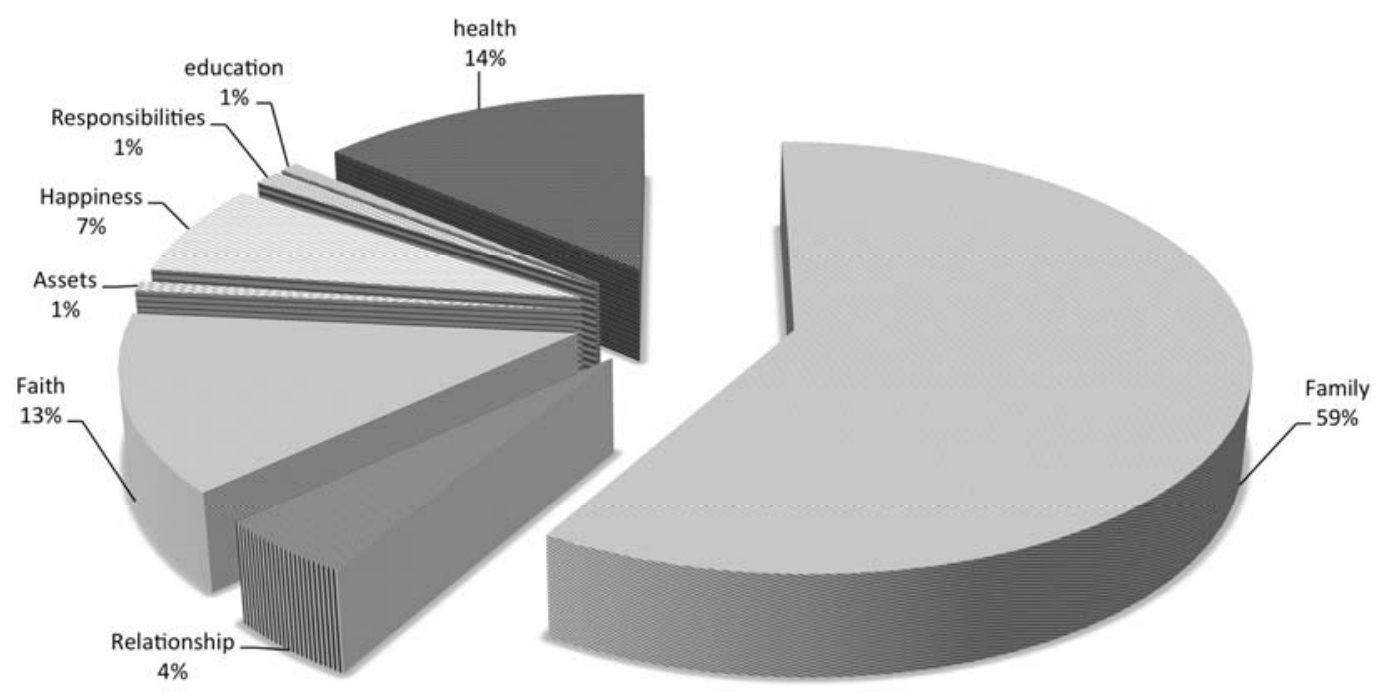

Figure 2. Gender Distribution of the Study Subjects

When subjects were asked regarding the most important asset in life, family was by far the most common first choice among all groups and individuals. 59\% of participants selected family as the most important thing in life followed by health (14\%) and faith (13\%) (see Figure 3).

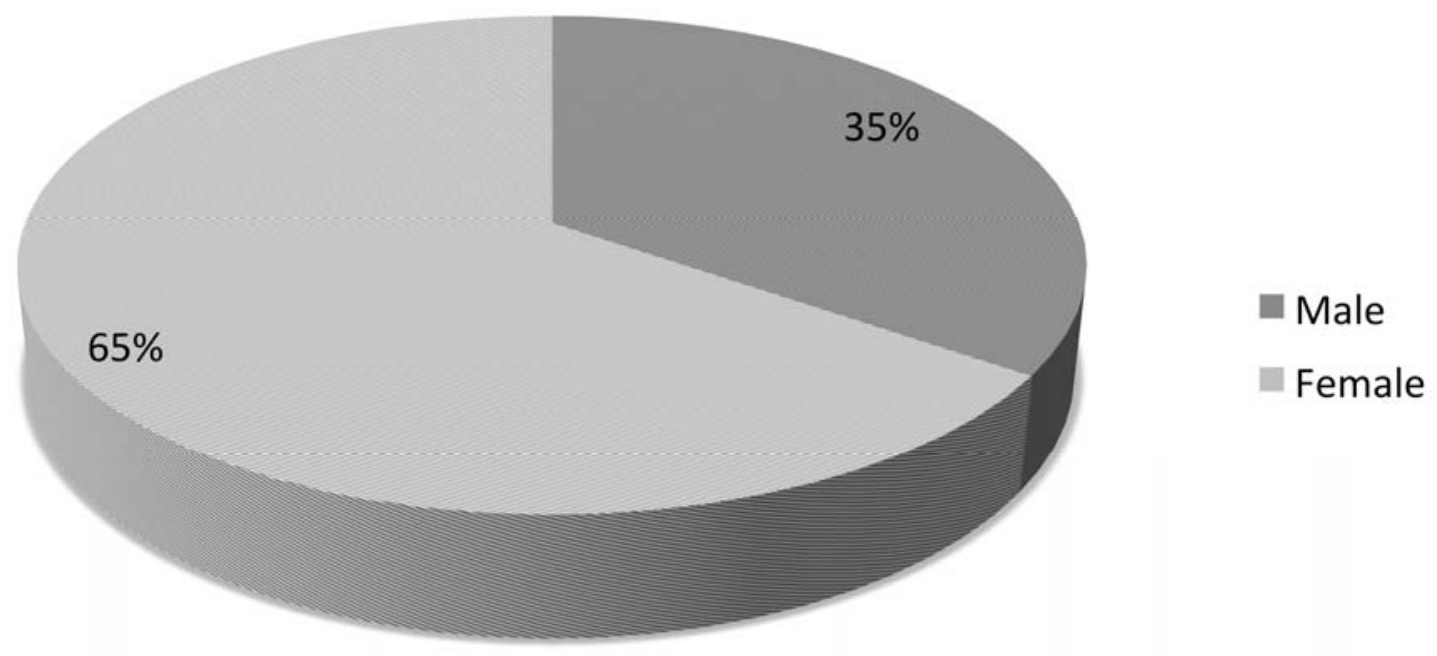

Figure 3. The Most Important Thing in Life

When the participants were asked to select their top three choices, happiness and relationships were also other top choices that made it to the top three choices (see Figure 4). 


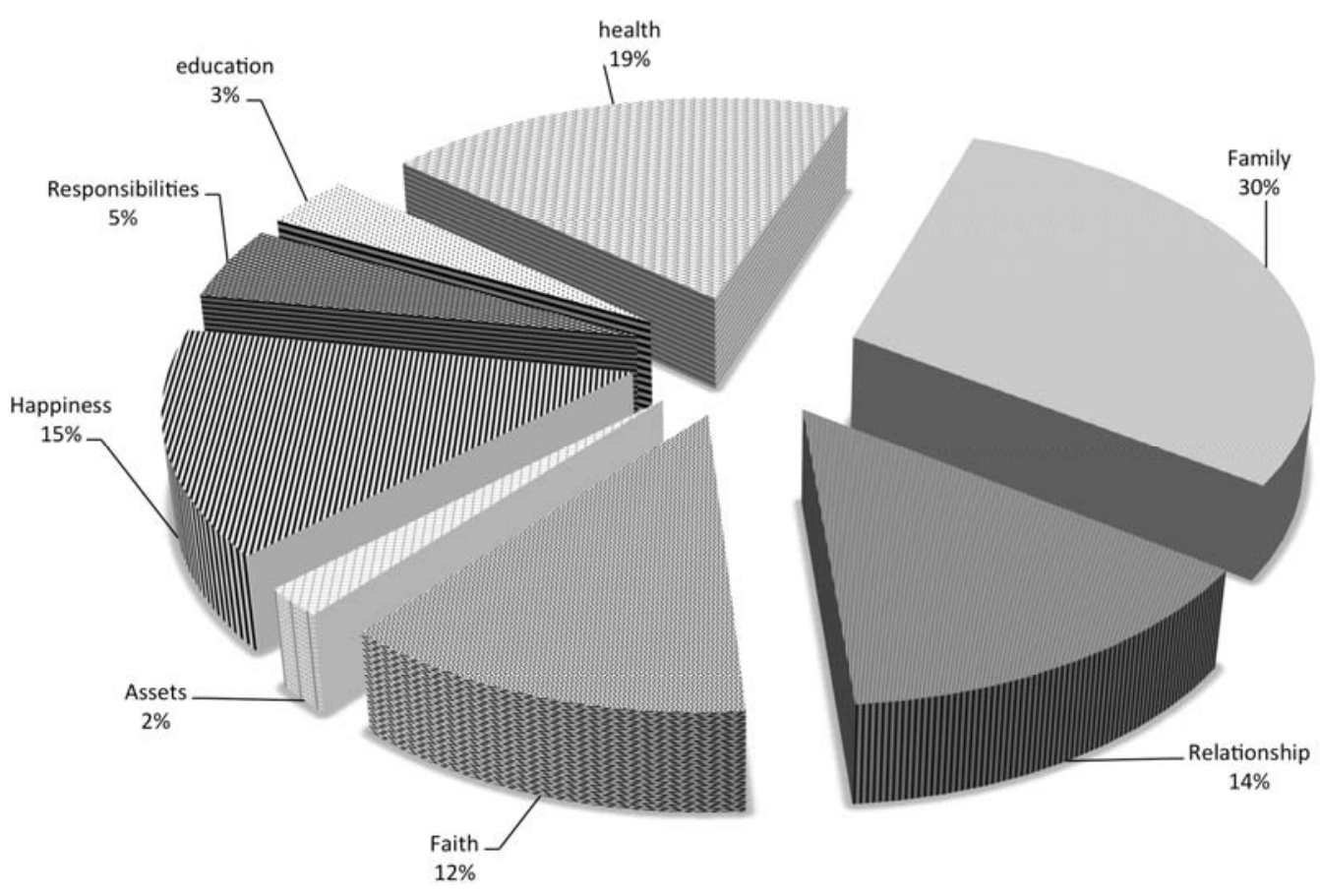

Figure 4. Top Three Most Important Things in Life

Gender played a significant role in individual selection. Family ranked significantly higher among females compared to males $(61 \%$ vs. $52 \%, \mathrm{p}=0.001)$ as the most important thing in life. The minor differences among the other ranked choices did not show any statistical significance between males and females. When comparing the data from the affluent US region and Panama, we did not find any significant differences in what the study subjects found to be important in life.

As mentioned previously, family was the most important thing in life for all test subjects. However, health was much more appreciated and ranked higher in older subjects compared to those who were middle aged or younger adults $(22 \%, 15 \%$, and $6 \%$, respectively, $\mathrm{p}=0.01)$. Conversely, happiness was less important to older subjects than middle aged and younger adults (3\%, 8\%, and $10 \%$, respectively). Surprisingly, faith was more important in younger subjects than middle aged and older adults (16\%, 15\%, and 9\%, respectively). Despite the observed trends, the difference in the importance of happiness and faith among different age groups did not achieve statistical significance.

When subjects were asked regarding the things that made them happy, love was by far the main topic that was selected among all groups and individuals. $29 \%$ of test subjects thought that being loved is what made them the happiest. This was closely followed by the desire to have someone to love and a sense of financial security as the top three most important things that made people happy (see Figure 5). However, older subjects significantly preferred to have someone to love compared to the middle age and younger adults (32\%, 20\%, and 22\%, respectively, $\mathrm{p}=0.011$ ).

Although the top three criteria that made people happy were similar for both genders, further down the rank of choices, females preferred being respected far more than males $(15 \%$ vs. $4 \%, p=0.004)$, while males considered having a passion in life as an important factor that made them happy $(14 \% \mathrm{vs.} 5 \%, \mathrm{p}=0.02)$. The minor differences among the other choices did not have any statistical significance between male and female subjects.

When comparing the data from the affluent US region and Panama, we found no significant differences among the top three criteria that made people happy. However, further down the ranked list, Panamanian subjects chose being respected as being far more important than the US subjects ( $18 \%$ vs. $10 \%, \mathrm{p}=0.029)$, whereas the US subjects considered being useful to something or someone as an important thing to keep them happy (11\% vs. $3 \%, \mathrm{p}=0.03$ ). 


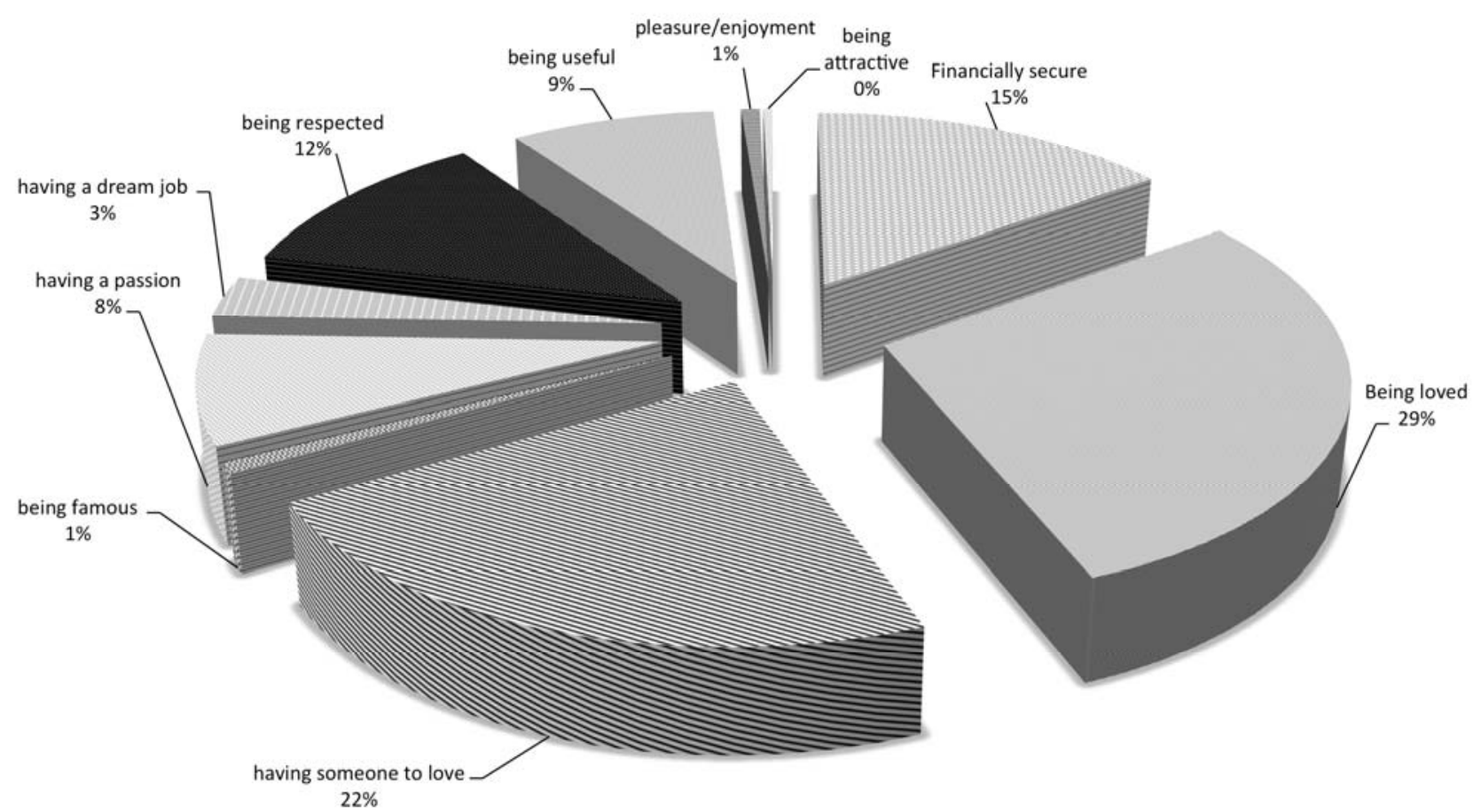

Figure 5. The Things That Make Us Happy

\section{Discussion}

There has been a wide gap in consensus among researchers regarding the use of measures of wellbeing and overall level of contentment (Zautra and Hempel, 1984; Linton et. al., 2015; Hervás and Vázquez, 2013), and there are even measures that determine the different type of happiness, such as eudemonic versus hedonic (Ryan and Deci, 2001; Diener, 2000; Waterman, 1993; Kashdan et. al., 2008; Keyes 2009). Some data suggest that the level of individual contentment is relatively stable over time (Koivumaa-Honkanen et. al., 2005), so it is important to tease out the factors that are involved in people's levels of contentment and happiness. This information may be particularly useful for possible intervention to modify the level of contentment in individuals dissatisfied with life. In fact, recent advances have prompted researchers to use various techniques to improve people's positive psychological outlook and level of happiness (Seligman et. al., 2005; Fava, 2015).

In this study we investigated factors that are important to people in general and also factors that could be important in people's overall happiness and contentment.

Our data suggests that family is by far the most important thing in life for the majority of test subjects, and is even more important in females than males. This stronger attachment of women to family is not surprising and studies have shown that working mothers spend an average of 14.2 hours per week on housework compared to 8.6 hours by fathers. In addition, there is no question that women more than men adjust their careers because of family life (Parker, 2016).

Family was followed by health and faith as the second and third most important life assets regardless of gender, age, or place of residence. As previously reported by other researchers, our data suggest that what we regard as the most important thing in life is somehow universal regardless of age, gender, and abode (Hogan et. al., 2016). Furthermore, our results suggest that people prefer intimate and social connections to material goods in order to be happy.

There is no doubt that there are some changes to what we regard as important aspects of life as we grow older (Hogan et. al., 2016), which agrees with our data since they show that, as we grow older, our attention becomes more focused on health as an important matter in life

The data also show that females prefer being respected while males like to have a passion as one of the factors that makes them happy. 
Our results could be helpful for designing questionnaires or surveys to measure the level of contentment or happiness. Alternatively, this information could be useful in pinpointing the factors that are important to people's overall sense of wellbeing and could be the target for a positive psychological intervention to improve it. This could be particularly beneficial to those with a poor level of contentment or dissatisfaction.

Our study had several shortcomings. First and foremost was the small number of participants, which could possibly have made interpretation of the results for the different subgroups underpowered. Even though we did not observe great differences between or trends in the major categories that we studied, we would have been likely to find more significant differences if we had had a larger number of participants. This is particularly true regarding the small group of cases that were recruited from Panama.

We opted to keep the questionnaire very simple to make it easier to understand and administer, and, for that purpose, we limited ourselves to have just one page of information and avoided asking too many personal, socioeconomic, and psychological questions. This increased our chance of recruiting more individuals who were willing to complete the questionnaire, but at the same time we forfeited collecting information that could have been useful in the interpretation such as level of income or other personal information in our study. Therefore, we consider this to be a pilot study for larger and more comprehensive studies on this very interesting subject.

Even though the questionnaire was completely anonymous, it is possible that the response of the individuals may have been biased toward answering what they thought should be the right answer rather than what they really thought. This may have shown itself by the very low number of participants who selected criteria such money and assets as one of the important things in life. In fact, this option did not even make it to the top five while, in real life, we see that a significant group of people seek this above all of the other selectable items. Similarly, seeking pleasure and enjoyment as one the major things that makes us happy did not make it to the top five in this study either, even though it is common knowledge that pleasure seeking is one the major motivations in people to make them happy.

\section{Conclusion}

It seems there is little difference in the criteria people regard as the most important thing in life and the things that make people happy among age groups or gender. Family is by far the most important thing in life for the majority and is followed by health and faith as the most important life assets regardless of gender, age, or place of residence. Love was by far the main thing that makes us happy. This was closely followed by a sense of financial security among all groups and individuals. In addition, despite thousands of miles of geographical separation and a very wide socioeconomic and educational gap between the two population groups in our study, there was no strong difference between what we regard as the most important thing in life and the things that make us happy. Further studies are needed to confirm the results of this preliminary report.

\section{References}

Diener E., \& Tay L. (2015). Subjective well-being and human welfare around the world as reflected in the Gallup World Poll. Int J Psychol., 50(2), 135-49. http://dx.doi.org/10.1002/ijop.12136

Diener E. (2000). Subjective well-being. The science of happiness and a proposal for a national index. Am Psychol., 55(1), 34-43. http://dx.doi.org/10.1037/0003-066X.55.1.34

Fava GA. (1999). Well-being therapy: conceptual and technical issues. Psychother Psychosom, 68(4), 171-9. http://dx.doi.org/10.1159/000012329

Hervás G., \& Vázquez C. (2013). Construction and validation of a measure of integrative well-being in seven languages: the Pemberton Happiness Index. Health Qual Life Outcomes, 11, 66. http://dx.doi.org/10.1186/1477-7525-11-66

Hogan MJ., Leyden KM., Conway R., Goldberg A., Walsh D., \& McKenna-Plumley PE. (2016). Happiness and health across the lifespan in five major cities: The impact of place and government performance. Soc Sci Med., 162, 168-76. http://dx.doi.org/10.1016/j.socscimed.2016.06.030

Kashdan TB., Diener RB., \& King LA. (2008). Reconsidering happiness: the costs of distinguishing between hedonics and eudaimonia. The Journal of Positive Psychology, 3(4), 219-233. http://dx.doi.org/10.1080/17439760802303044

Keyes CL, \& Annas J. (2009). Feeling good and functioning well: distinctive concepts in ancient philosophy and 
contemporary science. The Journal of Positive Psychology, 4(3), 197-201. http://dx.doi.org/10.1080/17439760902844228

Koivumaa-Honkanen H., Kaprio J., Honkanen RJ., Viinamäki H., \& Koskenvuo M. (2005). The stability of life satisfaction in a 15-year follow-up of adult Finns healthy at baseline. BMC Psychiatry, 5(4). http://dx.doi.org/10.1186/1471-244X-5-4

Linton MJ., Dieppe P., \& Medina-Lara A. (2015). Review of 99 self-report measures for assessing well-being in adults: exploring dimensions of well-being and developments over time. BMJ Open, 6(7), e010641. http://dx.doi.org/10.1136/bmjopen-2015-010641

Lyubomirsky S., King L., \& Diener E. (2005). The benefits of frequent positive affect: does happiness lead to success? Psychol Bull., 131(6), 803-55. http://dx.doi.org/10.1037/0033-2909.131.6.803

Parker K. (2010). Women more than men adjust their careers for family life. Pew research website/Fact-tank: Pew Research center. $\quad$ Retrieved $2010 \quad$ October from http://www.pewresearch.org/fact-tank/2015/10/01/women-more-than-men-adjust-their-careers-for-family-life/

Ryan RM., \& Deci EL. (2001). On happiness and human potentials: a review of research on hedonic and eudaimonic well-being. Annu Rev Psychol., 52, 141-66. http://dx.doi.org/10.1146/annurev.psych.52.1.141

Ryff CD. (1989). Happiness is everything, or is it? Explorations on the meaning of psychological well-being. Journal of Personality and Social Psychology, 57(6), 1069-1081. http://dx.doi.org/10.1037/0022-3514.57.6.1069

Seligman ME., Steen TA., Park N., \& Peterson C. (2005). Positive psychology progress: empirical validation of interventions. Am Psychol., 60(5), 410-21. http://dx.doi.org/10.1037/0003-066X.60.5.410

Waterman AS. (1993). Two conceptions of happiness: Contrasts of personal expressiveness (eudaimonia) and hedonic enjoyment. Journal of Personality and Social Psychology, 64(4), 678-691. http://dx.doi.org/10.1037/0022-3514.64.4.678

Zautra A, \& Hempel A. (1984). Subjective well-being and physical health: a narrative literature review with suggestions for future research. Int J Aging Hum Dev., 19(2), 91-110. http://dx.doi.org/10.2190/A9RB-7D02-G77K-M3N6 